\title{
The Effects of Nutrition Education and Gardening on Attitudes, Preferences, and Knowledge of Minority Second to Fifth Graders in the Rio Grande Valley Toward Fruit and Vegetables
}

\author{
Geralyn A. Nolan ${ }^{1}$, Amy L. McFarland², Jayne M. Zajicek ${ }^{3}$, \\ and Tina M. Waliczek ${ }^{4,5}$
}

Additional Index words. social issues, obesity, Type II diabetes, horticulture, health, fruit and vegetable questionnaire

SUMMARY. Child obesity has become a national concern. Obesity in children ages 6-17 years has more than doubled in the past 30 years. Only $20 \%$ of children today consume the recommended daily servings of fruit and vegetables. This trend is even more pronounced in minority populations. Past studies have reported a horticulture-based curriculum, including gardening, can improve children's attitudes toward eating fruit and vegetables. To investigate whether children of a minority population can benefit from gardening combined with a curriculum on nutrition, research was conducted with elementary schools in a primarily Hispanic region of Texas. Elementary school teachers participating in this research agreed to have school gardens and complete all activities in a curriculum on nutrition provided to them through the Texas Agrilife Extension Service. One hundred and forty-one children in the participating schools completed a pre- and posttest evaluating their nutritional knowledge, preference for fruit and vegetables, and snack choices before and after a gardening program supplemented with nutrition education. Differences were detected between pre- and posttest scores for all three variables. After comparing pre- and posttest scores, it was concluded that gardening and nutritional instruction had a positive effect on students' nutritional knowledge, fruit and vegetable preference (FVP), and snack choices.

$\mathrm{O}$ ver the years, children in America have consistently consumed fewer than the recommended servings of fruit and vegetables [Centers for Disease Control (CDC), 1996a; Cullen et al., 2001; Domel et al., 1993b; Krebs-Smith et al., 1996; Subar et al., 1995]. Instead, they are consuming high fat, caloric-dense, nutrient-poor foods. As a result, the number of overweight children has increased to record numbers (Blumenthal et al., 2002; CDC, 1996a). The prevalence of Type II diabetes in children is also on the rise (St.-Onge et al., 2003).

The consumption of fruit and vegetables is vital to the health of children (Bazzano et al., 2002; Cullen

${ }^{1}$ Graduate Assistant, Department of Horticultural Sciences, Texas A\&M University, College Station, TX 77843

${ }^{2}$ Haupt Fellow, Smithsonian Gardens, Smithsonian Institution, Washington, DC 20013

${ }^{3}$ Professor, Department of Horticultural Sciences, Texas A\&M University, College Station, TX 77843

${ }^{4}$ Professor, Department of Agriculture, Texas State University-San Marcos, San Marcos, TX 78666

${ }^{5}$ Corresponding author. E-mail: tc10@txstate.edu. et al., 2002; Djousse et al., 2004; Domel et al., 1993b; Kirby et al., 1995; Liu et al., 2000; Ness and Powles, 1997). Fruit and vegetable consumption decreases the risk for numerous diseases and health problems (Bazzano et al., 2002; Djousse et al., 2004; Liu et al., 2000). Including fruit and vegetables consistently in a diet can also assist with weight control (Lin and Morrison, 2002). This may be a result of fruit and vegetables being nutrient-dense and generally low in calories.

Low-income populations tend to consume even fewer fruit and vegetables and are at greater risk of being overweight and obese (Morton and Guthrie, 1999; Treiman et al., 1996; Wang, 2001). Often, fruit and vegetables are not available in the homes of low-income families because of areas of food deserts (areas without a proper grocery store) combined with the expense and perishable nature of fresh foods (Goodman, 2009; Treiman et al., 1996; Wang, 2001). Low-income families also report eating at fast food restaurants more frequently (Kirby et al., 1995). Research has reported many low-income families suffer from food insecurity, which is associated with a reduced variety and availability of fruit and vegetables at home (Dave et al., 2010; Kaiser et al., 2003; Matheson et al., 2002).

Additionally, research has suggested demographics influence risk levels for obesity and Type II diabetes. In the United States, the prevalence of overweight people and obesity is greatest among the lowincome groups (Morton and Guthrie, 1999; Wang, 2001). Cullen et al. (2002) found Hispanic children on average consumed fewer fruit and vegetables per day compared with non-Hispanic white children. Male Hispanics and the youngest and oldest age groups among Hispanics have reported the lowest intakes of fruit and vegetable servings per week (Subar et al., 1995). Furthermore, Hispanics are more likely to have a high body mass index compared with non-Hispanic whites (American Heart Association, 2011; Wang, 2001). Hispanic parents also report significantly fewer "meal planning practices" (such as making a menu before shopping) than nonHispanic white parents (Cullen et al., 2002).

Early childhood is a critical period for developing obesity (Law, 2001). The number of overweight children aged 6 to 17 has increased by almost $200 \%$ in the last 30 years and those numbers continue to rise in America (Blumenthal et al., 2002; CDC, 1996b; Jolliffe, 2004; Law, 2001; St.-Onge et al., 2003; Wang, 2001; Weisberg, 2002). About 30\% of children aged 6 to 19 years old are overweight (St.-Onge et al., 2003; Wang, 2001). According to the 20052008 National Health and Nutrition Examination Survey, only $31 \%$ of adult Americans are at a healthy weight, indicating many children are at risk for becoming overweight as adults $[\mathrm{Na}-$ tional Center for Health Statistics (NCHS), 2011]. Overweight individuals and the incidence of obesity has increased so rapidly both worldwide and within the United States that physicians are now calling it an epidemic and believe that it will soon pass smoking as the leading cause of preventable death within the United States (Blumenthal et al., 2002; Hesketh and Campbell, 2010; Weisberg, 2002). 
Diseases that result from being overweight or obese are believed to be responsible for $\approx 300,000$ deaths per year in the United States and have been estimated to cost in excess of $\$ 200$ billion annually for medical expenses and lost productivity (CDC, 1996b; NCHS, 2011; Weisberg, 2002).

Food preferences and dietary habits are established during childhood (Carter, 2002; Kirby et al., 1995). Therefore, interventions need to be targeted toward young children while they are forming their lifelong habits. Preference for and positive attitudes about fruit and vegetables have been major predictors of fruit and vegetable consumption (Cullen et al., 2002; Domel et al., 1993b; Reniscow et al., 1997). Since many chronic diseases begin in childhood and carry over into adulthood and dietary preferences are learned while children are young, strategies should be aimed at younger children to improve their preferences and attitudes toward fruit and vegetables (Baranowski et al., 1997). Strategies aimed at younger children tend to have better long-term results than strategies focused on adolescents (Carter, 2002).

There are many ways teachers can teach nutrition. School-based nutrition education increases nutritional knowledge and can influence positive attitude change toward healthy eating in most grade levels (Contento et al., 1992). School gardens are a way to teach students using hands-on activities that are fun and teach skills at the same time. Gardening provides handson activities through the actual growing, harvesting, and preparation of vegetables. Gardening and related activities improve attitudes about, preferences for, and willingness to taste new fruit and vegetables (Lineberger and Zajicek, 2000; Morris et al., 2001).

The objective of the current study was to evaluate the impact of a health education through gardening program on children's knowledge about nutrition and the attitudes they have toward fruit and vegetables.

\section{Materials and methods}

SAMPLE. The sample for this research study included participants from elementary schools in the Rio Grande Valley of Texas, a primarily Hispanic region. A pretest was conducted in August at the start of the school year, and a posttest was administered in March of the following year. Schools were recruited to participate through the Junior Master Gardener (JMG) program (Seagraves et al., 2005). The teachers who volunteered their classes to participate in this study attended a 6-d workshop presented by extension agents during the summer months. At the workshop, teachers observed demonstrations, participated in mini workshops, attended seminars, and went on a field trip to an orchard. In addition, teachers were given the curriculum to take back to their school to teach in their classrooms.

A total of 141 second-grade through fifth-grade students participated in this study. Complete data sets were collected from nine different classrooms in four different public schools in the Rio Grande Valley. The grade level of students in the study varied per school depending on the teachers who volunteered to participate. Most teachers reported that they taught all the concepts and completed most of the activities in the JMG program curriculum. A county extension agent ensured teachers' questions were addressed and that gardens were being used consistently over the study period.

According to the 2000 U.S. Census Bureau (USCB), there were 12,439 children aged 5 to 9 years in this region (USCB, 2000). The median household income was $\$ 23,799$ and $33 \%$ of the households earned $\$ 14,999$ or less in 1999. Of families with related children under 18 years of age, $42.2 \%$ had household incomes below the poverty line. Of those sampled by the USCB, $88.4 \%$ were Hispanic or Latino (USCB, 2000). In this study, of those sampled, $84.4 \%$ (119 of 141 ) reported to be Hispanic.

INSTRUMENT AND DATA COLLECTION. The instrument used for this study consisted of three sections. The first section was a modified version of the FVP questionnaire, which measured fourth and fifth graders' preference for fruit and vegetables (Domel et al., 1993b). The questionnaire was created and used to identify FVPs of fourth-and fifth-grade students participating in a health program targeting fruit and vegetable consumption (Domel et al., 1993b). This instrument was considered to be a "reliable, valid, and easy-to-administer tool for assessing fruit and vegetable preferences"
(Domel et al., 1993a) and reported internal consistency reliabilities of $\alpha=$ 0.70 for the vegetable portion of the questionnaire, $\alpha=0.73$ for the fruit portion of the questionnaire and $\alpha=$ 0.74 for the snack portion of the questionnaire (Domel et al., 1993b). In a study of second through fifth-grade students, this scale was again reported to be reliable and valid with an internal consistency reliabilities of $\alpha=0.85$ for the fruit portion of the questionnaire, $\alpha=0.81$ for the vegetable portion of the questionnaire, and $\alpha=0.79$ for the snack portion of the questionnaire (Lineberger and Zajicek, 2000). A county extension agent administered the pre- and posttests.

The FVP questionnaire was comprised of two distinct parts. The first consisted of a list of 10 fruit and vegetables. The students were asked to circle an answer for how they felt about a specific fruit or vegetable. Instead of numbers for choice ratings, students rated their preference with a face symbol. "I like this a lot" was a smiley face; "I like this a little" was a neutral face, and "I do not like this" was a frowning face. The second part consisted of 10 snack preference options. The students were asked to choose which they preferred most between fruit or vegetable snack and non-fruit or vegetable snack.

To analyze data, each answer received a score. The response "I like this a lot" was given a score of 2 points. The response "I like this a little" was given a score of 1 point. The response "I do not like this" was given 0 points. The points were summed so each participant received a preference score that ranged from 0 to 20 points. For the snack questionnaire, a student was given 1 point for choosing the fruit or vegetable snack and 0 points for choosing the non-fruit or vegetable snack item. The points were summed so each participant received a snack score that ranged from 0 to 10 points. The higher the score the better the FVP/attitude and snack preference/attitude.

The second section of the instrument used in this study contained 13 multiple-choice questions testing the knowledge that each student should have gained from the curriculum and gardening project. It asked questions regarding food groups, vitamin sources, serving amounts, and other nutrition-related questions. To 
analyze these questions, each correct answer received 1 point. An incorrect answer received 0 points. The scores were summed so each participant received a score ranging from 0 to 13 points. The higher the score, the more knowledge each student should have about fruit, vegetables, and nutrition.

Each questionnaire included a third section to collect demographic information including the student's gender, ethnicity, and grade level. These questions were modeled after previously published, similar studies (Koch et al., 2006). After the tests were returned, each test was coded with a number for each participant so the pretest and posttest could be matched.

Data analysis. Only students who completed all the testing were included in the data analysis. Data were entered into an electronic spreadsheet and analyzed using SPSS (version 12.0; IBM Corp., Armonk, NY). Paired $t$ tests were conducted to compare the pretest to posttest scores for each section of the instrument. Additional comparisons using two-factor analysis of variance (ANOVA) with repeated measures were performed to determine exactly where the differences occurred.

\section{Results and discussion}

Reliability of instrument. A Cronbach's reliability test for the knowledge portion of the instrument in this study resulted in a reliability coefficient of $\alpha=0.67$, a reliability coefficient of $\alpha=0.72$ for the FVP section, and a reliability coefficient of $\alpha=0.83$ for the fruit and vegetable snack choice section, showing this instrument to be a reliable measure (Gall et al., 2006).

Demographics. This sample included an almost equal split of male (64) and female participants (77). The majority of the sample was Hispanic (as targeted) (119), with a handful of African-American (5), Caucasian (13), and members of other ethnic groups (4). The sample was composed of second (31), third (52), fourth (22) and fifth (36) graders (as targeted) (Table 1).

NUTRITIONAL KNOWLEDGE SECTION. A repeated measures ANOVA revealed a main effect difference in the pretest to the posttest scores (Table 2). This indicated students scored higher on the nutritional knowledge test after completing the program compared with their scores at the start of the program. Previous research has also shown an increase in knowledge after an intervention (Domel et al., 1993a;

Howison et al., 1988; Lawatsch, 1990; Morris et al., 2002).

There was no interaction by gender which indicated that both males

Table 1. Demographic breakdown of sample in the study of the effects of nutrition education and gardening on attitudes, preferences, and knowledge of second-to-fifth graders in the Rio Grande Valley of Texas toward fruit and vegetables.

\begin{tabular}{lrcccc}
\hline $\begin{array}{l}\text { Survey section } \\
\text { demographic }\end{array}$ & $N$ & $\begin{array}{c}\text { Pretest } \\
\text { mean score }\end{array}$ & Pretest sD & $\begin{array}{c}\text { Posttest } \\
\text { mean score }\end{array}$ & Posttest \\
\hline $\begin{array}{l}\text { Nutrition knowledge }(0-13 \\
\text { Gender }\end{array}$ & & & & & \\
$\quad$ scale $)^{\mathrm{z}}$ & & & & \\
$\quad$ Male & 64 & 7.05 & 2.04 & 8.81 & 2.77 \\
$\quad \begin{array}{l}\text { Female } \\
\text { Ethnicity }\end{array}$ & 77 & 6.71 & 1.85 & 8.19 & 2.49 \\
$\quad$ Hispanic & 19 & 6.81 & 1.95 & 8.34 & 2.69 \\
Black & 5 & 7.00 & 2.12 & 8.60 & 0.89 \\
White & 13 & 7.38 & 1.90 & 9.85 & 2.27 \\
Other & 4 & 6.75 & 2.06 & 8.00 & 2.45 \\
Grade level & & & & & \\
$\quad$ Second & 31 & 6.65 & 1.64 & $8.90 \mathrm{a}^{\mathrm{y}}$ & 3.30 \\
$\quad \begin{array}{l}\text { Third } \\
\text { Fourth }\end{array}$ & 52 & 7.02 & 2.02 & $8.92 \mathrm{a}$ & 2.76 \\
Fifth & 22 & 6.09 & 2.00 & $8.09 \mathrm{a}$ & 2.11 \\
& 36 & 7.31 & 1.94 & $7.69 \mathrm{~b}$ & 1.80
\end{tabular}

Fruit and vegetable preference $(0-20 \text { scale })^{x}$

Gender

$\begin{array}{lrrrrr}\text { Male } & 64 & 11.31 & 3.87 & 12.38 & 4.61 \\ \quad \text { Female } & 77 & 12.49 & 3.33 & 12.92 & 3.66 \\ \text { Ethnicity } & & & & & \\ \quad \text { Hispanic } & 119 & 11.97 & 3.62 & 12.73 & 4.24 \\ \text { African-American } & 5 & 13.00 & 4.64 & 11.40 & 3.78 \\ \text { Caucasian } & 13 & 12.23 & 3.06 & 13.54 & 3.10 \\ \quad \text { Other } & 4 & 9.50 & 4.45 & 9.75 & 2.50 \\ \text { Grade level } & & & & & \\ \quad \text { Second } & 31 & 13.48 & 3.24 & 14.90 \mathrm{~cd}^{\mathrm{w}} & 3.93 \\ \text { Third } & 52 & 12.52 & 3.58 & 12.98 \mathrm{~cd} & 3.80 \\ \text { Fourth } & 22 & 10.73 & 3.47 & 11.50 \mathrm{~d} & 3.56 \\ \text { Fifth } & 36 & 10.58 & 3.48 & 11.03 \mathrm{e} & 4.19\end{array}$

Snack choice $(0-10 \text { scale })^{\mathrm{v}}$

Gender

$\begin{array}{lrllll}\text { Male } & 64 & 3.89 & 2.42 & 5.96 & 3.21 \\ \text { Female } & 77 & 4.78 & 2.57 & 6.78 & 2.91 \\ \text { Ethnicity } & & & & & \\ \text { Hispanic } & 119 & 4.51 & 2.6 & 6.35 & 3.09 \\ \text { Black } & 5 & 3.40 & 3.36 & 6.40 & 3.78 \\ \text { White } & 13 & 4.23 & 1.09 & 7.54 & 2.63 \\ \text { Other } & 4 & 2.00 & 0.82 & 4.25 & 1.71 \\ \text { Grade level } & & & & & \\ \text { Second } & 31 & 4.55 & 2.98 & 7.03 \mathrm{fg}^{\mathrm{u}} & 2.99 \\ \text { Third } & 52 & 4.63 & 2.41 & 7.13 \mathrm{~g} & 2.74 \\ \text { Fourth } & 22 & 3.18 & 1.87 & 6.18 \mathrm{f} & 3.17 \\ \text { Fifth } & 36 & 4.58 & 2.55 & 4.94 \mathrm{f} & 3.08\end{array}$

${ }^{\mathrm{z}}$ cores ranged from 0 to 13 with higher scores indicating more nutritional knowledge.

y Difference in nutritional knowledge posttest score means followed by the same letters within the column are not different according to least significant difference (LSD) test at the $P=0.05$ level.

${ }^{\mathrm{x}} \mathrm{S}$ cores ranged from 0 to 20 with higher scores indicating more preference for fruit and vegetables.

wDifference in fruit and vegetable preference pre- to posttest means followed by the same letters within the column are not different according to LSD test at the $P=0.05$ level.

${ }^{v}$ Scores ranged from 0 to 10 with higher scores indicating a healthier snack selected more frequently.

uDifference in snack choice pre- to posttest means followed by the same letters within the column are not different according to LSD test at the $P=0.05$ level. 
Table 2. Repeated measures analysis of variance for the nutritional knowledge scores in the study of the effects of nutrition education and gardening on attitudes, preferences, and knowledge of second-to-fifth graders in the Rio Grande Valley of Texas toward fruit and vegetables.

\begin{tabular}{|c|c|c|c|c|c|}
\hline Source of variation ${ }^{\mathrm{z}}$ & $\begin{array}{l}\text { Mean score } \\
(0-13 \text { scale })^{\mathrm{y}}\end{array}$ & SD & df & $\mathbf{F}$ & $P$ \\
\hline Pretest & 6.87 & 1.94 & 1 & 42.74 & 0.001 * \\
\hline Posttest & 8.48 & 2.62 & & & \\
\hline Pretest to posttest change $\times$ gender & & & 1 & 0.340 & 0.563 \\
\hline Pretest to posttest change $\times$ grade level $^{x}$ & & & 3 & 3.09 & $0.029 *$ \\
\hline
\end{tabular}

${ }^{\mathrm{z}} \mathrm{N}=141$ for both pre- and posttests.

y Scores ranged from 0 to 13 with higher scores indicating more nutritional knowledge.

${ }^{x}$ Grade levels in this study included second, third, fourth, and fifth.

* Significant at the $P=0.05$ level.

and females increased their knowledge scores from pretest to posttest, and there was no difference between the rate of change in scores of male and female students on the knowledge section of the survey. Male and female scores improved similarly from pretest to posttest.

However, a grade level interaction did exist where fifth graders had the highest pretest score but the lowest posttest score. The change from pretest to posttest knowledge scores for fifth-grade students was less than the change for all other grade levels (Table 1). Since the curriculum combined with gardening had a greater effect on the younger students, the activities may be better geared toward younger students. These findings support the research conducted by Carter (2002) and Baranowski et al. (1997) who found nutrition programming was best geared toward younger children and not adolescents.

FRUIT AND VEgETABLE PREFERENCE SECTION. An ANOVA revealed an increase from pretest to posttest scores on the FVP scores (Table 3 ). The results indicated a positive change in preference for fruit and vegetables after participating in the gardening and nutrition curriculum (Genzer et al., 2001). An improved attitude toward fruit and vegetables after an intervention has been found by previous research (Byrd-Bredbenner et al., 1993; Koch et al., 2006; Lawatsch, 1990; Lineberger and Zajicek, 2000).

There was no interaction by gender on the FVP scores of male and female students on the preference section of the survey. Male and female scores improved similarly from pretest to posttest and benefitted similarly from the program. There was also no interaction on the change from pretest to posttest by grade level, which indicated all grade levels benefitted similarly with regards to their indication of their FVPs.

However, there were main effects between the grade levels only on the posttest preference scores. A least significant difference (LSD) post hoc test was administered to investigate which grade levels were different at the end of the testing period (Table 1). Differences in the posttest scores were found between grades second and fourth $(P=0.001)$, second and fifth $(P=0.001)$, and third and fifth $(P=0.007)$. Second-graders scored higher compared with fourthand fifth-graders, and third-graders scored higher compared with fifthgraders on the posttest.

SNACK CHOICE. A repeated measures ANOVA revealed an increase from pretest to posttest snack choice scores (Table 4). The results indicated a positive change in preferences for fruit and vegetables after participating in the gardening and nutrition curriculum.

There was no interaction by gender indicating males and females benefitted similarly from the program with regards to their snack choices. However, a grade level interaction was found with regards to snack choices. An LSD post hoc test indicated differences between the posttest snack choice scores for third- and fourth-grades $(P=0.033)$ and third- and fifthgrades $(P=0.020)$ (Table 1$)$. Thirdgraders scored higher on the posttest snack scores compared with fourth- and fifth-graders, while third- and secondgraders scored similarly to each other. These findings reinforce supporting nutrition programming for younger children as suggested by the research conducted by Carter (2002) and Baranowski et al. (1997).

\section{Limitations of the study}

An in-depth training session for this curriculum was provided and required for all teachers that volunteered their classes for research. However, there was no follow-up to ensure they implemented the curriculum correctly. Therefore, future researchers need to develop a process to evaluate the implementation of the curriculum to ensure it is standardized.

This research concentrated on assessing the participants' nutritional knowledge, and attitudes and preferences for fruit and vegetables. It did not measure nutritional behavior. Repetition of this study using different evaluation tools that include behavior should be conducted. Examples of possible ways to measure changes in behavior might include having the student actually choose a snack (rather than having them hypothetically select one on paper), telling the student they have $\$ 1$ and ask them what they would buy with that $\$ 1$, or a 24 -h recall diary repeated several times throughout the study.

In addition, repetition of this study should be conducted using students of different ages and populations. This may include younger children - kindergarten and first-grade students, or older children with a revised curriculumreevaluating fourth and fifth graders, and including junior-high and/or highschool aged students. Future research could also look at different socioeconomic status populations to determine how a gardening curriculum would affect their nutritional knowledge, attitudes, and behavior.

\section{Conclusion}

Elementary students who were taught a nutrition curriculum while actively participating in gardening significantly improved their nutritional knowledge, preference for fruit and vegetables and chose a fruit or vegetable snack over a non-healthy snack more frequently after the program. The significant improvement in nutritional knowledge scores, FVP scores, and snack choice scores indicated the handson nutrition curriculum combined with active participation in gardening can be used to influence elementary children's attitudes and preferences regarding fruit and vegetables and improve their knowledge about nutrition. However, it did not have the same effect on all 
Table 3. Repeated measures analysis of variance for the fruit and vegetable preference scores in the study of the effects of nutrition education and gardening on attitudes, preferences, and knowledge of second-to-fifth graders in the Rio Grande Valley of Texas toward fruit and vegetables.

\begin{tabular}{|c|c|c|c|c|c|}
\hline Source of variation ${ }^{\mathrm{z}}$ & $\begin{array}{l}\text { Mean score } \\
(0-20 \text { scale })^{\mathrm{y}}\end{array}$ & SD & df & $\mathbf{F}$ & $P$ \\
\hline Pretest & 11.96 & 3.62 & 1 & 6.72 & 0.011 * \\
\hline Posttest & 12.67 & 4.11 & & & \\
\hline Pretest to posttest change $\times$ gender & & & 1 & 1.22 & 0.272 \\
\hline Pretest to posttest change $\times$ grade level $^{\mathrm{x}}$ & & & 3 & 0.612 & 0.608 \\
\hline
\end{tabular}

${ }^{\mathrm{z}} \mathrm{N}=141$ for both pre- and posttests.

y cores ranged from 0 to 20 with higher scores indicating more preference for fruit and vegetables.

${ }^{x}$ Grade levels in this study included second, third, fourth, and fifth.

* Significant at the $P=0.05$ level.

Table 4. Repeated measures analysis of variance for the snack choice scores in the study of the effects of nutrition education and gardening on attitudes, preferences, and knowledge of second-to-fifth graders in the Rio Grande Valley of Texas toward fruit and vegetables.

\begin{tabular}{lccccc}
\hline Source of variation & Mean score & & & & \\
\hline Pretest & $(\mathbf{0}-\mathbf{1 0} \text { scale })^{\mathbf{y}}$ & SD & df & F & $\boldsymbol{P}$ \\
Posttest & 4.38 & 2.54 & 1 & 49.20 & $0.001^{*}$ \\
Pretest to posttest change $\times$ gender & 6.40 & 3.06 & & & \\
Pretest to posttest change $\times$ grade level $^{\mathrm{x}}$ & & & 1 & 0.012 & 0.914 \\
\hline
\end{tabular}

${ }^{\mathrm{z}} \mathrm{N}=141$ for both pre- and posttests.

y Scores ranged from 0 to 10 with higher scores indicating a healthier snack selected more frequently.

${ }^{x}$ Grade levels in this study included second, third, fourth, and fifth.

* Significant at the $P=0.05$ level.

ages. The younger students, in second and third grades, had more positive outcomes compared with the fourthand, especially, fifth-grade participants. This may be an indication the curriculum was not targeting the older children and may need to be adapted for older age groups.

\section{Literature cited}

American Heart Association. 2011. Overweight in Children. 12 Mar. 2012. <http: //www.heart.org/HEARTORG/Get tingHealthy/Overweight-in-Children_ UCM_304054_Article.jsp>.

Baranowski, T., M. Smith, M. Hearn, L. Lin, J. Baranowski, C. Doyle, K. Reniscow, and D. Wang. 1997. Patterns in children's fruit and vegetable consumption by meal and day of the week. J. Amer. Coll. Nutr. 16:216-223.

Bazzano, L., J. He, L. Ogden, C. Loria, S. Vupputuri, L. Myers, and P. Whelton. 2002. Fruit and vegetable intake and risk of cardiovascular disease in US adults: The first national health and nutrition examination survey epidemiologic follow-up study. Amer. J. Clin. Nutr. 76:93-99.

Blumenthal, S.J., J. Hendi, and L. Marsillo. 2002. A public health approach to decreasing obesity. J. Amer. Medical Assn. 228: 2176-2181.
Byrd-Bredbenner, C., M.L. Marecic, and J. Bernstein. 1993. Development of a nutrition education curriculum for head start children. J. Nutr. Educ. 25:134-139.

Carter, R.C. 2002. The impact of public schools on childhood obesity. J. Amer. Medical Assn. 288:2180.

Centers for Disease Control. 1996a. Summary of CDC's guidelines for school health programs to promote lifelong healthy eating. J. Nutr. Educ. 29:45-46.

Centers for Disease Control. 1996b. Guidelines for school health programs to promote lifelong healthy eating. Centers Disease Control Prevention 45:1-41.

Contento, I.R., A. Manning, and B. Shannon. 1992. Research perspective on school based nutrition education. J. Nutr. Educ. 24:247-260.

Cullen, K.W., T. Baranowski, E. Owens, C. de Moor, L. Rittenberry, N. Olvera, and K. Resnicow. 2002. Ethnic differences in social correlates of diet. Health Educ. Res. 17:7-18.

Cullen, K.W., T. Baranowski, L. Rittenberry, C. Cosart, D. Herbert, and C. de Moor. 2001. Child-reported family and peer influences on fruit, juice and vegetable consumption: Reliability and validity measures. Health Educ. Res. 16:187-200.

Dave, J.M., A.E. Evans, K.A. Pfeiffer, K.W. Watkins, and R.P. Saunders. 2010.
Correlates of availability and accessibility of fruits and vegetables in homes of lowincome Hispanic families. Health Educ. Res. 25:97-108.

Djousse, L., D. Arnett, H. Coon, M. Province, L. Moore, and C. Ellison. 2004. Fruit and vegetable consumption and LDL cholesterol: The National Heart, Lung, and Blood Institute Family Heart Study. Amer. J. Clin. Nutr. 79: 213-217.

Domel, S.B., T. Baranowski, H. Davis, S. Leonard, P. Riley, and J. Baranowski. 1993a. Measuring fruit and vegetable preferences among fourth-and fifth-grade students. Prev. Med. 22:866-879.

Domel, S.B., T. Baranowski, H. Davis, W. Thompson, S. Leonard, P. Riley, J. Baranowski, B. Dudovitz, and M. Smyth. 1993b. Development and evaluation of a school intervention to increase fruit and vegetable consumption among fourth and fifth grade students. J. Nutr. Educ. 25: 345-349.

Gall, M.D., W.R. Borg, and J.P. Gall. 2006. Educational research: An introduction. 8th ed. Allyn and Bacon, White Plains, NY.

Genzer, S., R. Seagraves, L. Whittlesey, C.W. Robinson, and S. Koch. 2001. Junior Master Gardener Level 1 Golden Ray: Health and nutrition from the garden. Newman Publishing, Bryan, TX.

Goodman, D. 2009. Place and Space in Alternative Food Networks: Connecting Production and Consumption. 12 Mar. 2012. <http://www.kcl.ac.uk/content/ 1/c6/03/95/42/GoodmanWP21.pdfs.

Hesketh, K.D. and K.J. Campbell. 2010. Interventions to prevent obesity in $0-5$ year olds: An updated systematic review of the literature. Obesity (Silver Spring) 18:S27-S35.

Howison, D., F. Niedermyer, and R. Shortridge. 1988. Field testing a fifthgrade nutrition education program designed to change food-selection behavior. J. Nutr. Educ. 20:82-86.

Jolliffe, D. 2004. Extent of overweight among US children and adolescents from 1971 to 2000. Intl. J. Obes. 28:4-9.

Kaiser, L.L., H. Melgar-Quinonez, M.S. Townsend, Y. Nicholson, M.L. Fujii, A.C. Martin, and C.L. Lamp. 2003. Food insecurity and food supplies in Latino households with young children. J. Nutr. Educ. Behav. 35:148-153.

Kirby, S.D., T. Baranowski, K.D. Reynolds, G. Taylor, and D. Brinkley. 1995. Children's fruit and vegetable intake: Socioeconomic, adult-child, regional, and urban-rural influences. J. Nutr. Educ. 27:261-271. 
Koch, S., T.M. Waliczek, and J.M. Zajicek. 2006. The effect of a summer gardening program on the nutritional knowledge, attitudes, and behaviors of children. HortTechnology 16:620-625.

Krebs-Smith, S.M., D.A. Cook, A.F. Subar, L. Cleveland, J. Friday, and L.L. Kahle. 1996. Fruit and vegetable intakes of children and adolescents in the United States. Arch. Pediatr. Adolesc. Med. 150:81-86.

Law, C. 2001. Adult obesity and growth in childhood: Children who grow rapidly during childhood are more likely to be obese as adults. BMJ 323:1320-1321.

Lawatsch, D.E. 1990. A comparison of two teaching strategies on nutrition knowledge, attitudes and food behavior of preschool children. J. Nutr. Educ. 22:117-123.

Lin, B. and R.M. Morrison. 2002. Higher fruit consumption linked with lower body mass index. FoodReview 25:28-32.

Lineberger, S. and J.M. Zajicek. 2000. School gardens: Can a hands-on teaching tool affect students' attitudes and behaviors regarding fruit and vegetables? HortTechnology 10:23-27.

Liu, S., J. Manson, I. Lee, S. Cole, C. Hennekens, W. Willett, and J. Buring. 2000. Fruit and vegetable intake and risk of cardiovascular disease: The Woman's Health Study. Amer. J. Clin. Nutr. 72:922-928
Matheson, D.M., J. Varady, A. Varady, and J.D. Killen. 2002. Household food insecurity and nutritional status of Hispanic children in the fifth grade. Amer. J. Clin. Nutr. 76:210-217.

Morris, J.L., A. Neustadter, and S. Zidenberg-Cherr. 2001. First-grade gardeners more likely to taste vegetables. Calif. Agr. 55:43-46.

Morris, J.L., A. Neustadter, and S. Zidenberg-Cherr. 2002. Garden-enhanced nutrition curriculum improves fourth-grade school children's knowledge of nutrition and preferences for some vegetables. J. Amer. Dietetic Assn. 102:91-93.

Morton, J.F. and J.F. Guthrie. 1999. Diet related knowledge, attitudes, and practices of low income households with children. J. Early Educ. Family Rev. 6:26-33.

National Center for Health Statistics. 2011. Healthy People 2010: Final Review. 9 Feb. 2012. <http://www.cdc.gov/ nchs/data/hpdata2010/hp2010_final_ review.pdf $>$.

Ness, A. and J. Powles. 1997. Fruit and vegetables, and cardiovascular disease: A review. Intl. J. Epidemiol. 26:1-13.

Reniscow, K., T. Baranowski, and M. Hearn. 1997. Social cognitive predictors of fruit and vegetable intake in children. Health Psychol. 16:272-276.

Seagraves, R.L., L. Whittlesey, C. Klemmer, C.W. Robinson, G. Hall, S.S. Genzer, C.
Lewis, and S. Grahmann. 2005. Junior Master Gardener: Level 1 teacher/leader guide. Texas A\&M Agr. Commun., College Station, TX.

St.-Onge, M., K.L. Keller, and S.B. Heymsfield. 2003. Changes in childhood food consumption patterns: A cause for concern in light of increasing body weights. Amer. J. Clin. Nutr. 78:1068-1073.

Subar, A., J. Heimendinger, B. Patterson, S. Krebs-Smith, E. Pivonka, and R. Kessler. 1995. Fruit and vegetable intake in the United States: The baseline survey of the five a day for better health program. Amer. J. Health Promot. 9:352-360.

Treiman, K., V. Freimuth, D. Damron, A. Lasswell, J. Anliker, S. Havas, P. Langenberg, and R. Feldman. 1996. Attitudes and behaviors related to fruits and vegetables among low-income women in the WIC program. J. Nutr. Educ. 28:149-156.

U.S. Census Bureau. 2000. U.S. Census Bureau. 12 Mar. 2012. <http://www. census.gov/>.

Wang, Y. 2001. Cross national comparison of childhood obesity: The epidemic and the relationship between obesity and socioeconomic status. Intl. J. Epidemiol. 30:1129-1136.

Weisberg, S.P. 2002. Societal change to prevent obesity. J. Amer. Medical Assn. 288:2176-2181. 